\title{
Diaǵnóstico de baixa visão em crianças: sentimentos e compreensão de mães
}

\author{
Diagnosis of low vision in children: feelings and comprehension of mothers
}

\author{
Mirela de Oliveira Figueiredo ${ }^{1}$ \\ Roberto Benedito de Paiva e Silva ${ }^{2}$ \\ Maria Inês Rubo Nobre ${ }^{3}$
}

\section{RESUMO}

Objetivos: Identificar os sentimentos e reações de mães perante ao diagnóstico de baixa visão do filho e a sua compreensão do diagnóstico. Métodos: Este estudo caracteriza-se como uma pesquisa qualitativa. Foram entrevistadas 11 mães de crianças com baixa visão atendidas pelo Serviço de Estimulação Visual do Setor de Oftalmologia Hospital de Clínicas da Unicamp. Para a coleta dos dados foram utilizadas entrevistas semiestruturadas. Os tópicos principais da entrevista foram: sentimentos diante do diagnóstico e a compreensão do diagnóstico da baixa visão. Resultados: As mães apresentaram medo de que o filho fique cego e compreensão não clara da baixa visão, interpretando o diagnóstico médico de acordo com a sua subjetividade. Conclusões: A maneira como o diagnóstico é transmitido para as famílias é de extrema importância. As condições culturais, econômicas e emocionais dos pais, na maioria das vezes podem impedir a compreensão clara do diagnóstico.

Descritores: Baixa visão/diagnóstico; Baixa visão/psicologia; Emoções; Comportamento materno; Relações mãe-filho; Compreensão

pinas - UNICAMP - Campinas (SP) - Brasil.

${ }^{1}$ Mestranda do Curso de Pós-Graduação em Saúde da Criança e do Adolescente do Centro de Investigação em Pediatria da Faculdade de Ciências Médicas da Universidade Estadual de Campinas - UNICAMP - Campinas (SP) - Brasil.

${ }^{2}$ Professor Doutor do Centro de Estudos e Pesquisas em Reabilitação "Prof. Dr. Gabriel Porto", Faculdade de Ciências Médicas da UNICAMP - Campinas (SP) - Brasil

${ }^{3}$ Assessora Doutora de Centros de Estudos e Pesquisas em Reabilitação "Prof. Dr. Gabriel Porto", Faculdade de Ciências Médicas da UNICAMP - Campinas (SP) Brasil.

Endereço para correspondência: Mirela de Oliveira Figueiredo. Rua Boa Morte, 1.246 - Limeira (SP) CEP 13480-754

E-mail: mirelafigueiredo@yahoo.com.br

Recebido para publicação em 09.01.2008

Última versão recebida em 17.04.2009

Aprovação em 29.10.2009

*Este artigo é parte da dissertação de mestrado: "Diagnóstico de baixa visão em crianças: sentimentos e representação de mães", desenvolvida no Curso de Pós-Graduação em Saúde da Criança e do Adolescente do Centro de Investigação em Pediatria da Faculdade de Ciências Médicas da Unicamp.

Nota Editorial: Depois de concluída a análise do artigo sob sigilo editorial e com a anuência da Dra. Celina Tamaki Monteiro de Castro sobre a divulgação de seu nome como revisora, agradecemos sua participação neste processo.

\section{INTRODUÇÃO}

A chegada de um filho portador de deficiência visual provoca profundas mudanças nos hábitos familiares e condiciona as atividades sociais da família. É tão forte a evidência da nova situação que se pode falar dos sonhos e projetos da mãe antes do nascimento de seu filho deficiente, em contraposição aos sonhos e projetos depois deste acontecimento ${ }^{(1)}$.

A transmissão de um diagnóstico é um atributo do ato médico e um direito do paciente ter acesso. O momento dessa transmissão e a forma como é feita é muito importante, representa um processo de escuta, investigação e análise que ocorre a partir da ajuda solicitada pelo paciente ao seu médico. É a partir do diagnóstico que o médico e a equipe elaboram e planejam o tratamento e que o paciente se organiza e programa os passos para lidar com a doença. O fato de o paciente saber o nome e entender as implicações de sua doença possibilita que ele repense sua realidade, programando sua vida dentro de novos contornos e com autonomia ${ }^{(2)}$.

O objetivo deste estudo foi identificar sentimentos e reações de mães perante o diagnóstico e a compreensão da baixa visão de seus filhos.
\end{abstract}

\section{MÉTODOS}

Este estudo caracteriza-se como uma pesquisa qualitativa. A abordagem qualitativa considera que o sujeito vive em determinada condição e classe 
social, têm suas crenças, valores e significados, é complexo, contraditório, inacabado e em permanente transformação $0^{(3)}$.

O estudo qualitativo busca uma compreensão particular daquilo que estuda, não se preocupa com generalizações. $\mathrm{O}$ foco da atenção neste tipo de pesquisa é o específico, o peculiar, o individual, almejando sempre a compreensão dos fenômenos estudados ${ }^{(4)}$.

\section{Participantes do estudo}

Os participantes desse estudo são mães ou responsáveis de crianças com baixa visão, com idade entre 0 a 4 anos, atendidas pelo Serviço de Estimulação Visual do Setor de Oftalmologia do HC da Unicamp, que foram escolhidas de forma intencional.

A seleção das participantes foi realizada no período de novembro de 2005 a setembro de 2006, incluído neste período o estudo exploratório, no qual o pesquisador entra em contato com enfoques, percepções e terminologias novas para ele, contribuindo para que, paulatinamente, seu próprio modo de pensar seja modificado ${ }^{(5)}$.

Para encerrar a coleta de dados utilizou-se a amostragem por saturação. Na medida em que as entrevistas ocorriam, as mesmas eram transcritas literalmente. Desta forma, na $11^{\underline{a}}$ entrevista verificou-se que alguns dados já estavam repetitivos e considerando-se que já havia um número suficiente de entrevistas para se chegar aos objetivos propostos pela pesquisa, decidiu-se que não haveria necessidade de incluir mais participantes no estudo. A amostra ficou composta por dez mães, e em um caso pela avó como responsável e cuidadora da neta, que nesse estudo será designada como mãe.

\section{Procedimentos}

Para a coleta dos dados foi utilizada entrevista semiestruturada $^{(6)}$, para qual foi elaborado um roteiro de entrevista composto de tópicos que, se não fossem tratados espontaneamente pelas participantes, seriam abordados pela pesquisadora. Os tópicos principais para este estudo foram: sentimentos perante o diagnóstico e a compreensão do diagnóstico.
As entrevistas foram gravadas com equipamento de áudio-cassete e realizadas no Serviço de Estimulação Visual do Setor de Oftalmologia do HC da Unicamp, após a obtenção do consentimento livre e esclarecido, segundo a Resolução 196/ 96 do Conselho Nacional da Saúde e aprovado pelo Comitê de Ética e Pesquisa da FCM - Unicamp.

\section{RESULTADOS}

As entrevistas gravadas foram transcritas integralmente tornando os relatos dos entrevistados em dados. Para o tratamento dos dados foi utilizada a técnica de análise de conteúdo ${ }^{(7)}$, do tipo temática e categorial.

A partir do tema, estudar a vivência das mães perante o diagnóstico da baixa visão do filho foram escolhidas duas categorias que, juntas, podem responder aos objetivos do estudo. São elas: sentimentos perante o diagnóstico da baixa visão e a compreensão do diagnóstico e da causa da baixa visão.

\section{DISCUSSÃO}

\section{Sentimentos ao diagnóstico da baixa visão}

Todas as mães quando questionadas sobre o que sentiram no momento em que souberam do problema visual do filho se referiram ao sentimento de medo. $\mathrm{O}$ medo referido pelas mães se deve ao fato de elas não conhecerem a doença e/ou de conhecerem alguém que não enxergava, e com isso, sentiram medo de que seus filhos ficassem cegos. Como exemplo temos o relato da mãe 10 .

"Ah, eu achei assim que ele ia ficar com problema né no olho, que não ia enxergar. Depois que eu vi, no dia que eu cheguei no hospital, que a gente tava aqui, aqui nele tava tudo machucado. Eu cheguei lá, vi o olho do menino e chorei a noite inteira. Aí a médica: não foi nada bem, não precisa chorar. Ah, eu fiquei desesperada, por causa do jeito que tava o olho dele, dele perdê a visão, o meu medo eraesse" (M 10).

\begin{tabular}{|c|c|c|c|c|c|c|}
\hline \multicolumn{7}{|c|}{ Quadro 1. Caracterização sociocultural e econômica das participantes } \\
\hline Mãe & Idade & Escolaridade & Profissão & Estado civil & № de filhos & Renda \\
\hline $1^{*}$ & 52 & $2^{a}$ série E.F. & Trabalhava/atualmente do lar & Casada & 3 & 3 S.M. \\
\hline 2 & 25 & $7^{\mathrm{a}}$ série E.F. & Trabalhava/atualmente do lar & Casada & 1 & 2 S.M. \\
\hline 3 & 23 & E.M. & Do lar para cuidar do filho & Casada & 2 & 2 S.M. \\
\hline 4 & 22 & E.F. & Do lar/nunca trabalhou & Casada & 1 & 4 S.M. \\
\hline 5 & 24 & E.F. & Do lar para cuidar do filho & Casada & 1 & 2 S.M. \\
\hline 6 & 27 & E.F. & Trabalhava/atualmente do lar & Casada & 2 & 4 S.M. \\
\hline 7 & 31 & $4^{a}$ série E.F. & Do lar para cuidar do filho & União estável & 2 & 2 S.M. \\
\hline 8 & 25 & $2^{\circ}$ ano E.M. & Trabalhava/atualmente do lar & Casada & 2 & 4 S.M. \\
\hline 9 & 36 & E.M. & Do lar para cuidar do filho & Casada & 1 & 4 S.M. \\
\hline 10 & 23 & E.F. & Do lar para cuidar do filho & Casada & 1 & 2 S.M. \\
\hline 11 & 23 & E.F. & Do lar/nunca trabalhou & União estável & 3 & 4 S.M. \\
\hline
\end{tabular}




\section{Identificação:}

Criança №:

Idade da criança no $1^{\circ}$ atendimento no SVSNI:

Idade da criança no $1^{\circ}$ atendimento na Estimulação Visual:

Diagnóstico:

Entrevistado: Mãe [ ] Pai [ ] Outro [ ]

\section{Caracterização sociodemográfica:}

Número de filhos:

Quantas pessoas moram no domicílio:

Quantas pessoas trabalham na família?

Renda salarial da família: 1 a 2 salários mínimos ( )

5 a 6 salários mínimos ( )

3 a 4 salários mínimos ( )

$>7$ salários mínimos ( )

\section{Roteiro para entrevista com os pais:}

1) Qual o motivo do seu filho(a) ter sido encaminhado para a Unicamp?

2) Você recebeu alguma informação sobre a causa da perda visual do seu filho(a)? Qual?

3) O que você sentiu no momento em que soube que teu filho(a) tinha problema visual?

4) Antes de vir para o SVSNI da Unicamp você já conhecia alguém com problema parecido com o do seu filho(a)?

5) Explicaram para você o motivo do encaminhamento para a estimulação visual?

6) Se sim, você acha que a estimulação visual pode ajudar o teu filho(a)? Em que?

7) Você recebeu alguma orientação sobre a estimulação visual? Qual?

8) Você tinha dúvidas em relação à perda visual de seu filho e sobre a estimulação visual? Estas dúvidas foram solucionadas?

9) Quais as expectativas em relação ao futuro de seu filho(a)?

10) Seu filho tem retorno marcado para novas consultas? Você tem dificuldades para vir às consultas?

O medo apresenta-se acompanhado de outros sentimentos, como o desespero, a tristeza, a raiva, a revolta e a não aceitação. Nessa fase, é difícil admitir a deficiência e na maioria das vezes a mãe reage emocionalmente como o relato das mães a seguir:

"Aí eu fiquei nervosa e comecei a brigar lá mesmo, porque falei que meu filho não era cego. De jeito nenhum que ele é cego. Aí eles falavam: então como ele não pega os objetos? Ele não pega por que não quer, falei assim. Poxa fiquei nervosa” (M 5).

"Ah, eu senti um pouco de tudo na época. No começo muita revolta, eu não assumia. A gente não assume né. Por exemplo, quando uma pessoa pega e fala pra você: ah, o que tem no olhinho dele, parece que tá com problema. Nossa eu ficava nervosa quando a pessoa perguntava isso. Ficava até com raiva” (M 2).

Algumas mães referiram que ficaram tão arrasadas que chegaram a sentir-se deprimidas, como exemplo temos o relato da mãe 8 .

"Ah, no começo é difícil pra aceitar, pra mim foi difícil pra aceitar tudo o que ele tinha, aí no começo tive depressão, fiquei doente" (M 8).

O sentimento de culpa nessas situações também pode ser esperado, pois a não concretização do sonho do filho nascer e corresponder com as expectativas desencadeia na mãe a sensação de que ela errou e de que ela é culpada pelos aconteci$\operatorname{mentos}^{(8)}$. A mãe 11 relata:

“Ah, me senti péssima, né. Culpada, me senti muito péssima mesmo. Ah, porque assim às vezes a gente pensa: aí será que eu tomei alguma coisa que fez mal na gestação, né, será que foi algum remédio que eu não prestei atenção, ou muito nervoso" (M 11).

Apesar de todas as mães terem no início apresentado uma mescla de sentimentos desagradáveis, duas delas demonstraram superação das fases iniciais de sobrevivência ${ }^{(1)}$ e busca, partindo para o ajustamento, pois conforme o filho foi se desenvolvendo receberam apoio de profissionais e puderam trocar experiências com outras mães que vivenciavam situações similares. As mães referem:

“Agora hoje não, hoje eu já falo de uma maneira mais natural do assunto. Principalmente depois que eu vim pra Unicamp. Porque a gente realmente vê que, assim, tem muita pessoa que sofre muito mais que a gente. $O$ problema da gente não é nada perto do que a outra pessoa. E de conversar com as mães mesmo, aqui na Unicamp” (M 2).

"Mas hoje eu posso dizer que tô bem uns 80, 90\%, não tem nem comparação, mas mesmo assim, nesse estado emocional que eu fiquei, eu não abandonei meu filho, não cheguei a rejeitar ele nem nada, ergui a cabeça, Deus me deu força, bastante apoio também dos colegas, das pessoas” (M 9).

\section{Compreensão do diagnóstico e da causa da baixa visão}

A compreensão do diagnóstico está intimamente relacionada com as condições sociais, culturais, históricas e com a 
forma de reagir perante o acometimento ${ }^{(9-10)}$. As reações desencadeadas diante de um acometimento podem ser explicadas pelas representações que cada indivíduo tem acerca desse acontecimento e que foi construído pelas formas de conhecimento do mundo a sua volta e a sua compreensão da realidade.

Em relação à compreensão do diagnóstico e da causa da baixa visão as mães o fazem da maneira como compreendem a partir de seu contexto sócio, cultural e educacional. Como exemplo temos o relato da mãe 1:

"Eles diz que é estrabismo, né. É esse olhinho tortinho dela, né, ela olhar pra gente e olhar torto, fica piscando, tremendo o olhinho. Olha a informação que falaram é que é de família, é genético" (M 1).

Criança possui diagnóstico de amaurose congênita de Leber

A doença, seu diagnóstico e suas alterações são interpretados não só pelo médico como também pelo doente e sua família. Seguindo os princípios da antropologia médica, que ressalta a importância de perceber a saúde por uma perspectiva cultural, ou seja, abordar a doença e seu impacto por meio de um processo subjetivo e coletivo, que engloba valores, regras, crenças e expectativas, sendo assim plausível de inúmeras interpretações.

Todas as pessoas envolvidas no processo de adoecimento, doente, família e equipe médica constroem um conjunto de ideias sobre o assunto. Este conjunto de ideias, é definido como modelo explicativo, e atua gerando explicações sobre a etiologia da doença, a maneira e momento de seu surgimento, seus processos patofisiológicos, seu curso e nível de gravidade e, finalmente, os tratamentos apropriados ${ }^{(9)}$. No caso de modelos formulados por familiares, ou seja, de pessoas que não possuem formação teórica sobre o assunto e não são profissionais da área, estes são fortemente influenciados por questões subjetivas, de personalidade e culturais. A mãe 9 conseguiu construir o seu modelo explicativo para a situação de enfermidade do filho:

"[...] a retina descolou [...] e até onde cheguei tô bem esclarecida. Só se alguma coisa que eu não saiba, mas até onde chegou aqui, o que aconteceu com ele, ele é prematuro, o problema dele é de nascença, então quanto aí, eu não tenho dúvida nenhuma. É, ela falou que foi por causa da prematuridade, né. Ah, segundo o que a doutora me falou o olho não tava formado, se não tava formado, tava formando, ele recebeu oxigênio, então o oxigênio afetou a retina e descolou" (M 9).

Criança com diagnóstico de retinopatia da prematuridade.

Já no caso de modelos gerados por profissionais de saúde, esses se referem, primordialmente, à lógica da ciência médica e não a fatores socioculturais do paciente. Nesse contexto que surge a discrepância entre o que o profissional explica para o paciente e sua família, sua forma de explicar e abordar os conteúdos, com o que o paciente compreende e é capaz de compreender ${ }^{(10)}$.

Algumas mães sabem que o filho tem baixa visão, mas não sabem dizer o nome do diagnóstico completo, apresentando um pouco de confusão, demonstrando os seus processos de construção de modelos explicativos. Foi o que se notou no relato da mãe 2:

"O nome especifico não, porque parece que não é só um nome de alguma coisa, assim, parece que não é só aquilo, que é mais coisa, mais pra mim até decorar, tem um relatório. É que foi provavelmente durante a minha gravidez. É num relatório também está escrito que pode ter sido na incubadora porque ele nasceu prematuro, né, mas, igual a pediatra de lá falou: não tem como né T., porque tinha que salvar a vida dele, ele nasceu com 1,190 kg, o pulmão dele era fechadinho e não tinha como, ele tinha que ficar, né, no balão de oxigênio. Mas aqui chegaram a falar pra mim que foi durante a minha gravidez" (M 2).

Criança possui diagnóstico de persistência de vítreo primário hiperplásico.

Os padrões de educação, o nível socioeconômico e os hábitos e crenças de uma comunidade são fatores que influenciam na importância que o indivíduo dá à visão e estimula o grau de cuidado que terá para protegê-la. Neste sentido, compreender um diagnóstico e internalizar os conteúdos relatados pelo oftalmologista, bem como saber passá-los com veracidade não é tarefa fácil e depende de inúmeros fatores ${ }^{(11)}$.

Oito das mães demonstram não saberem e/ou não lembrarem o diagnóstico e a causa da baixa visão. A compreensão do diagnóstico, como já dito, está diretamente relacionada com o modo como esta mãe recebeu as informações, o momento em que estava vivendo e como interpretou o que lhe foi dito segundo suas condições de vida. Nota-se a dificuldade de compreensão do diagnóstico nos relatos de algumas mães como exemplo a mãe 5:

"Eu ainda num sei por que ele ainda aumenta cada vez mais o óculos. Porque falam que ele enxerga pouquinho, mas eles ficando entre eles e não fala o que ele tem realmente. Que nem, até mandar o papel do Cierp para eu ficar mais tranquila porque eu sei que ele enxerga pouquinho mais não sei explicar bastante o que que ele tem. O médico falou assim que era por causa do nascimento dele, que a falta de oxigênio afetou o lado esquerdo, né. Que uma visão dele é mais baixa que a outra" (M 5).

Criança com diagnóstico de baixa visão central em decorrência da paralisia cerebral e hipóxia neonatal, apresentando também estrabismo no olho esquerdo.

O desconhecimento da dificuldade visual retrata que a forma dos indivíduos cuidarem da saúde, valorizar a visão, compreender a doença e colocar em prática as orientações fornecidas pelos profissionais está intimamente ligada às condições psicossociais, culturais e históricas inerentes ao indivíduo. Por este motivo, sinaliza-se a necessidade de transformações nas práticas dos profissionais da área da saúde, pois algumas mães apesar de estarem frequentando a vários anos os consultórios médicos, apresentam um desconhecimento da real necessidade do filho. É o que se observa no relato a seguir:

“Ah, eu não lembro. Eu não lembro já faz tanto tempo. O médico falou que podia ser e a terapeuta também falou que podia ter sido por isso. Por causa da hidrocefalia porque 
às vezes aífica sequela, e ficou a sequela na visão. Ah, num sei por que, assim aconteceu pra ele ficar assim" (M 4). Criança com diagnóstico de baixa acuidade visual de origem central em decorrência a hidrocefalia, estrabismo divergente e nistagmo horizontal.

Cabe ressaltar, a importância da maneira como o diagnóstico é transmitido para as famílias, sendo necessário que o médico leve em consideração as condições culturais, econômicas e emocionais dos pais, pois, na maioria das vezes, essas situações podem interferir na compreensão clara do diagnóstico e na criação de expectativas condizentes com a realidade da criança.

\section{CONCLUSÕES}

Verificou-se que receber o diagnóstico de que o filho tem uma deficiência foi desestruturante para todas as mães participantes deste estudo, que referiram diversos sentimentos ao impacto do diagnóstico como o medo de que o filho fique cego, o desespero, a revolta, a tristeza e a raiva.

Notou-se que as participantes não compreenderam com clareza o diagnóstico de baixa visão. Tal fato pode ocorrer, pois cada mãe interpreta o diagnóstico médico de acordo com a sua subjetividade, receptividade para recebimento das informações fornecidas pela equipe médica, levando em consideração o seu contexto sociocultural.

Cabe ressaltar, a importância da maneira como o diagnóstico é transmitido para as famílias, sendo necessário que o médico leve em consideração as condições culturais, econômicas e emocionais dos pais.

Após o diagnóstico, torna-se claro a importância de uma intervenção que forneça o acolhimento a essas famílias, escutando, explicando as dúvidas em relação ao diagnóstico médico e proporcionando o atendimento adequado à criança com baixa visão.

\section{ABSTRACT}

Purpose: To identify mothers' feeling and reactions when fa- cing the diagnosis of low vision and their comprehension of this diagnosis. Methods: This study features a qualitative research. Eleven low vision children's mothers attended at the Visual Stimulation Service of Ophtalmology Sector of Unicamp Hospital were interviewed. Semi-strutured interviews were used to collect data. The main issues of the interview were: feelings when faced with the diagnosis and comprehension of this low vision diagnosis. Results: The results revealed mothers' fear of blindness and a low comprehension of the meaning of low vision, and their interpretation of medical diagnosis according to their subjectivity. Conclusions: The way the diagnosis is transmitted to the families is extremely important. Parents cultural, economical and emocional background may often impair the diagnosis comprehension.

Keywords: Vision, low/diagnosis; Vision, low/psicology; Emotions; Maternal behavior; Mother-child relations; Comprehension

\section{REFERÊNCIAS}

1. Miller NB. Ninguém é perfeito. Vivendo e crescendo com crianças que têm necessidades especiais. Campinas: Papirus; 1995.

2. Lecussán P. A criança e o diagnóstico: o pediatra deve contar à criança doente seu diagnóstico? Rev Assoc Med Bras. 2001;47(4):282-3.

3. Minayo MC. O desafio do conhecimento: pesquisa qualitativa em saúde. São Paulo: Hucitec; 1993.

4. Martins J, Bicudo MA. A pesquisa qualitativa em Psicologia. São Paulo: Moraes Educ; 1989.

5. Piovesan A, Temporini ER. Pesquisa exploratória: procedimento metodologico para o estudo de fatores humanos no campo da saúde pública. Rev Saúde Públ. 1995;29(4):318-25.

6. Cortes SM. Técnicas de coleta e análise qualitativa de dados. Cad Sociol. 1998; 9:1-47.

7. Bardin L. Análise de conteúdo. Lisboa: Personna; 1994.

8. Garcia Bruno MM. O desenvolvimento integral do portador de deficiência visual: da intervenção precoce à integração escolar. São Paulo: Newswork; 1993.

9. Kleinman A. Patient and healers in the context of the culture. California: University of California Presse; 1980.

10. Helman, CG. Cultura, Saúde e doença. $2^{\underline{a}}$ ed. Porto Alegre: Artes Médicas; 1994.

11. Temporini ER. Ação preventiva em problemas visuais de escolares. Rev Saúde Pública. 1984;18(3):259-62. 